\title{
Design of Photovoltaic Power Supply MPPT Circuit for WSN Node Based on Current Observation
}

\author{
https://doi.org/10.3991/ijoe.v14i07.8495 \\ Lieping Zhang $\left(^{\bowtie}\right)$, Yanlin Yu, Hang Ma, Yu Zhang \\ Guilin University of Technology, Guilin, China \\ zlp_gx_gl@163.com \\ Peng Cao \\ Guangdong University of Technology, Guangzhou, China
}

\begin{abstract}
In view of the problem of low energy collection efficiency and low efficiency of photovoltaic power supply modules in wireless sensor networks, a maximum power point tracking algorithm suitable for photovoltaic power supply of wireless sensor nodes is proposed. Firstly, the photovoltaic cell model is analyzed. Based on this, the traditional maximum power point tracking algorithm is analyzed. Combining with the advantages of disturbance observing method and load current maximization method, the problem of low working efficiency and low energy collection efficiency of functional modules is solved. Current observation method maximum power point tracking algorithm, and complete the relevant hardware circuit design. Experimental results show that the power consumption of MPPT circuit is low, and the efficiency caused by environmental factors is very small. The efficiency is kept above $90 \%$ and the overall system efficiency is about $87 \%$, which provides a stable and reliable photovoltaic power supply for WSN nodes.
\end{abstract}

Keywords-WSN Node, MPPT, Photovoltaic Power Supply, Current Observation

\section{Introduction}

As a new information acquisition and processing technology, wireless sensor network(WSN) can monitor, perceive and collect the relevant information of various monitored objects in the network distribution area in real time and has a bright future. However, WSN nodes are generally powered by common chemical batteries, and their limited service life directly affects the life of wireless sensor networks [1-2]. Taking the solar energy with higher energy density as the energy source of the wireless sensor node can greatly increase the life span of the wireless sensor node. Due to the low photoelectric conversion efficiency of photovoltaic cells, and the output power is greatly affected by external parameters such as light intensity and temperature, if it is necessary to ensure that the node obtains more energy to facilitate the storage of the energy storage element and improve the service quality of the node, To ensure that 
the photovoltaic cell output maximum power programmers [3]. In order to improve the energy conversion efficiency of photovoltaic cells, the maximum power point tracking (MPPT) technology is of great significance as far as possible to ensure that it works in the vicinity of the maximum power point in the environment [4].

Currently, there are many kinds of maximum power point tracking methods. According to the difference between judgment criteria and methods, they can be divided into open-loop MPPT algorithm, closed-loop MPPT algorithm and intelligent MPPT control algorithm[5]. The open-loop MPPT algorithm mainly includes constant voltage method,short-circuit current proportional coefficient method and difference calculation method. The closed-loop MPPT algorithm mainly includes disturbance observation method and conductance incremental method [6]. The intelligent control algorithm mainly includes MPPT control algorithm based on neural network, Fuzzy theory MPPT control algorithm [7-9]. In the research of MPPT algorithm in recent years, the literature [10] adopted the method of moving average conductance increment to control the voltage change. Simulation results show that this method is improved by $50 \%-60 \%$ compared with direct charging, but in the experiment, an additional $35 \%$ power loss due to processor calculations. The literature [11] proposed a bi-directional perturbation MPPT perturbation observation algorithm, by continuously comparing the output power of two-way perturbation, adaptively adjust the hysteresis width and quickly approaching the maximum power point. The literature [12] based on the open-circuit voltage method Collar battery, to avoid the occurrence of a periodic momentary off load to reduce the stability of the system, but also saves the maximum power point tracking power consumption, but the use of pilot battery has increased the cost of the system and the overall area of the circuit. In the literature [13], an improved variable-step algorithm based on $\beta$-parameter is proposed in this paper, which uses proportional coefficients of different sizes for the rise and fall of light intensity to reduce the power loss caused by the oscillation near the maximum power point. According to different degrees of influence of photovoltaic power generation on power generation efficiency, the literature [14] constructs the membership function of fuzzy factor, integrates the fuzzy weight of influencing factors into the structure of asymmetric neural network, and obtains the high-precision tracking of the maximum power point. However, the algorithm is computationally intensive and requires high control system.

In this paper, firstly, the MPPT algorithm based on the current observation method is proposed for the miniature photovoltaic system. Then, the MPPT hardware circuit for current observation is designed. Finally, the tracking effect of current observation MPPT algorithm is verified through simulation and experiment,MPPT circuit conversion efficiency. 


\section{Photovoltaic Cell Modeling and Output Characteristics Analysis}

\subsection{Photovoltaic cell analysis and modeling}

When the photovoltaic cells are exposed to sunlight, the circuit will produce current, and with the increase of light intensity, the photocurrent will increase continuously. When the illumination intensity is relatively stable, the equivalent circuit of the photovoltaic cell under the ideal state is as shown in Fig. 1 (a). The photovoltaic cell is equivalent to a constant current source and a diode $\left(D_{j}\right)$ in parallel. The photovoltaic cell produces photocurrent $\left(I_{p h}\right)$. The junction current of the PN junctionis $I_{D}$, the current supplied to the load $R_{L}$ is $I_{L}$, and $U_{O C}$ is the open circuit voltage. But in reality, it is necessary to consider the photovoltaic cell production material with its own incidental resistance $R_{s h}$ and production process caused by a small scratch resistance $R_{s}$, the load current is $I_{L}^{\prime}$. The actual form of photovoltaic cells shown is as shown in Figure 1 (b).

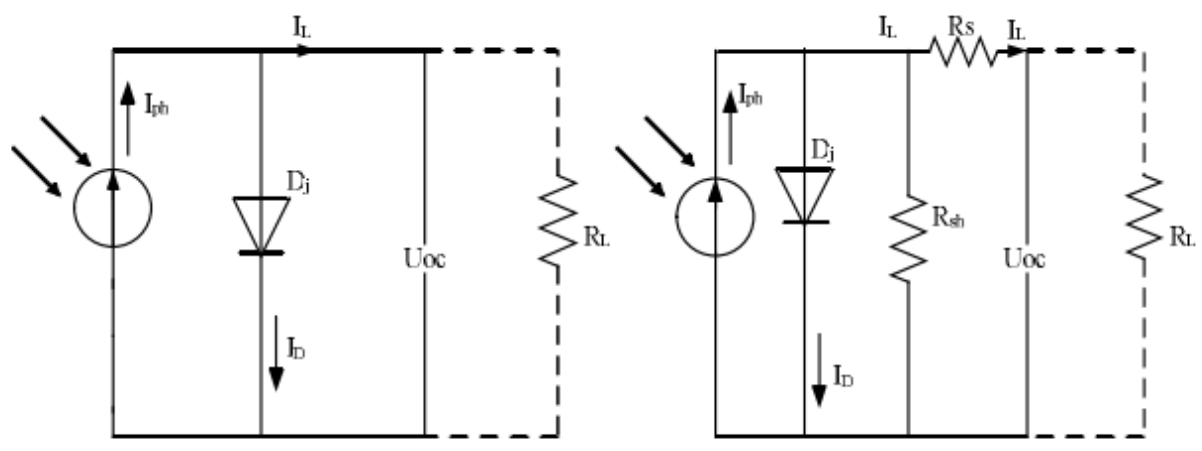

(a) Ideal situation(b) Actual situation

Fig. 1. The header image of online-journals.org

From Figure 1 (b) obtained photovoltaic cell current expression is:

$$
\mathrm{I}_{\mathrm{L}}^{\prime}=\mathrm{I}_{\mathrm{ph}}-\mathrm{I}_{\mathrm{D}}-\mathrm{I}_{\mathrm{sh}}
$$

By the photocurrent principle:

$$
\mathrm{I}_{\mathrm{ph}}=\frac{\mathrm{ISC}_{\mathrm{SC}}}{\mathrm{G}_{\mathrm{ref}}}+\mathrm{G}\left(\mathrm{T}-\mathrm{T}_{\mathrm{ref}}\right)
$$

In the equation (2): $I_{S C}$ is shortcircuit current; Sis the illumination area of the photovoltaic panel; $\mathrm{G}_{\text {ref }}$ is the light intensity under standard conditions; $G$ is the light intensity; $\mathrm{T}$ is the photovoltaic panel surface temperature; $\mathrm{T}_{\mathrm{ref}}$ is the photovoltaic panel surface temperatureunder standard conditions. By diode schottky equation: 


$$
\mathrm{I}_{\mathrm{D}}=\mathrm{I}_{\mathrm{O}}\left\{\exp \left[\frac{\mathrm{q}\left(\mathrm{U}+\mathrm{I}_{\mathrm{L}}^{\prime} \mathrm{R}_{\mathrm{S}}\right)}{\mathrm{AKT}}\right]-1\right\}
$$

In the equation (3): $\mathrm{I}_{\mathrm{O}}$ is the saturation current; $\mathrm{U}$ is the photovoltaic cell output voltage; $\mathrm{q}$ is the electron charge $\left(1.6 \times 10^{-19} \mathrm{C}\right)$; $\mathrm{A}$ is the diode ideality factor (The value is $[1-2]), \mathrm{K}$ is the Boltzmann constant $\left(1.38 \times 10^{-23} \mathrm{~J} / \mathrm{K}\right), \mathrm{T}$ is the temperature of the photovoltaic panel $(\mathrm{K})$.

Because $R_{s}$ is generally less than $1 \mathrm{ohm}, \mathrm{R}_{\mathrm{s}}$ is much smaller than $\mathrm{R}_{\mathrm{sh}}$, so $\mathrm{R}_{\mathrm{s}}$ and $\mathrm{I}_{\mathrm{sh}}$ can be ignored, the mathematical model is simplified as:

$$
\mathrm{I}=\frac{\mathrm{ISC}_{\mathrm{SS}}}{\mathrm{G}_{\mathrm{ref}}}+\mathrm{G}\left(\mathrm{T}-\mathrm{T}_{\mathrm{ref}}\right)-\mathrm{I}_{\mathrm{O}}\left\{\exp \left[\frac{\mathrm{qU}}{\mathrm{AKT}}\right]-1\right\}
$$

According to the parameters in the standard environment and the proportional relationship of the parameters in the actual environment, the output characteristic curves of photovoltaic cells under different illumination intensities and temperature changes are calculated according to the formulas (5) - (11) [15].

$$
\begin{aligned}
& \mathrm{I}_{\mathrm{SC}}=\mathrm{I}_{\mathrm{SC}^{*}} \cdot \frac{\mathrm{G}}{\mathrm{G}_{\mathrm{ref}}} \cdot(1+\mathrm{a} \Delta \mathrm{T}) \\
& \mathrm{U}_{\mathrm{OC}}=\mathrm{U}_{\mathrm{OC}^{*}} \cdot \ln (\mathrm{e}+\mathrm{b} \Delta \mathrm{G}) \cdot(1-\mathrm{c} \Delta \mathrm{T}) \\
& \mathrm{I}_{\mathrm{m}}=\mathrm{I}_{\mathrm{m}^{*}} \cdot \frac{\mathrm{G}}{\mathrm{G}_{\mathrm{ref}}} \cdot(1+\mathrm{a} \Delta \mathrm{T}) \\
& \mathrm{U}_{\mathrm{m}}=\mathrm{U}_{\mathrm{m}^{*}} \cdot \ln (\mathrm{e}+\mathrm{b} \Delta \mathrm{G}) \cdot(1-\mathrm{c} \Delta \mathrm{T}) \\
& \mathrm{P}_{\mathrm{PV}}=\mathrm{P}_{\mathrm{ref}} \cdot \frac{\mathrm{G}}{\mathrm{G}_{\mathrm{ref}}} \cdot[1+\mathrm{K} \Delta \mathrm{T}] \\
& \Delta \mathrm{T}=\mathrm{T}-\mathrm{T}_{\mathrm{ref}} \\
& \Delta \mathrm{G}=\mathrm{G}-\mathrm{G}_{\mathrm{ref}}
\end{aligned}
$$

In equations (5) - (11), $\mathrm{I}_{\mathrm{SC}}$ is the actual shortcircuit current; $\mathrm{U}_{\mathrm{OC}}$ is the actual open circuit voltage; $I_{m}$ is the actual peak current; $U_{m}$ is the actual peak voltage; $I_{S C^{*}}$ is the shortcircuit current under standard conditions; $\mathrm{U}_{\mathrm{OC}^{*}}$ is the open circuit voltage under standard conditions; $\mathrm{U}_{\mathrm{m}^{*}}$ is the peak voltage under standard conditions; $\mathrm{T}$ is the ambient temperature; $\mathrm{G}$ is the light intensity; $\Delta \mathrm{T}$ isthe difference between the actual temperature and the temperature under standard conditions. $\Delta$ Gisthe difference between the actual light intensity and the light intensity under standard conditions. The standard temperature and standard light intensity are $25^{\circ} \mathrm{Cand} 1000 \mathrm{~W} / \mathrm{m}^{2}$; a, b and c are the compensation coefficients, the values are $0.0025,0.0005$ and 0.0028 respectively [16-17].

The photovoltaic cell is polycrystalline silicon cell, the standard temperature $\left(25^{\circ} \mathrm{C}\right)$ and the standard light intensity $\left(1000 \mathrm{~W} / \mathrm{m}^{2}\right)$ environment parameters as shown in Table 1. 
Table 1. Photovoltaic cell technical parameters

\begin{tabular}{|c|c|c|c|}
\hline $\begin{array}{c}\text { Open circuit voltage } \\
\left(\mathbf{U}_{\mathbf{o c}}\right)\end{array}$ & $\begin{array}{c}\text { Short circuit current } \\
\left(\mathbf{I}_{\mathbf{s C}}\right)\end{array}$ & $\begin{array}{c}\text { Peak voltage } \\
\left(\mathbf{U}_{\mathbf{m}}\right)\end{array}$ & $\begin{array}{c}\text { Peak current } \\
\left(\mathbf{I}_{\mathbf{m}}\right)\end{array}$ \\
\hline $12.7 \mathrm{~V}$ & $0.42 \mathrm{~A}$ & $8.5 \mathrm{~V}$ & $0.35 \mathrm{~A}$ \\
\hline
\end{tabular}

According to the equations (5) (11) and the parameter of Table $\square$, the simulation model of photovoltaic is constructed by Matlab/Simulink, as shown in Fig 2.

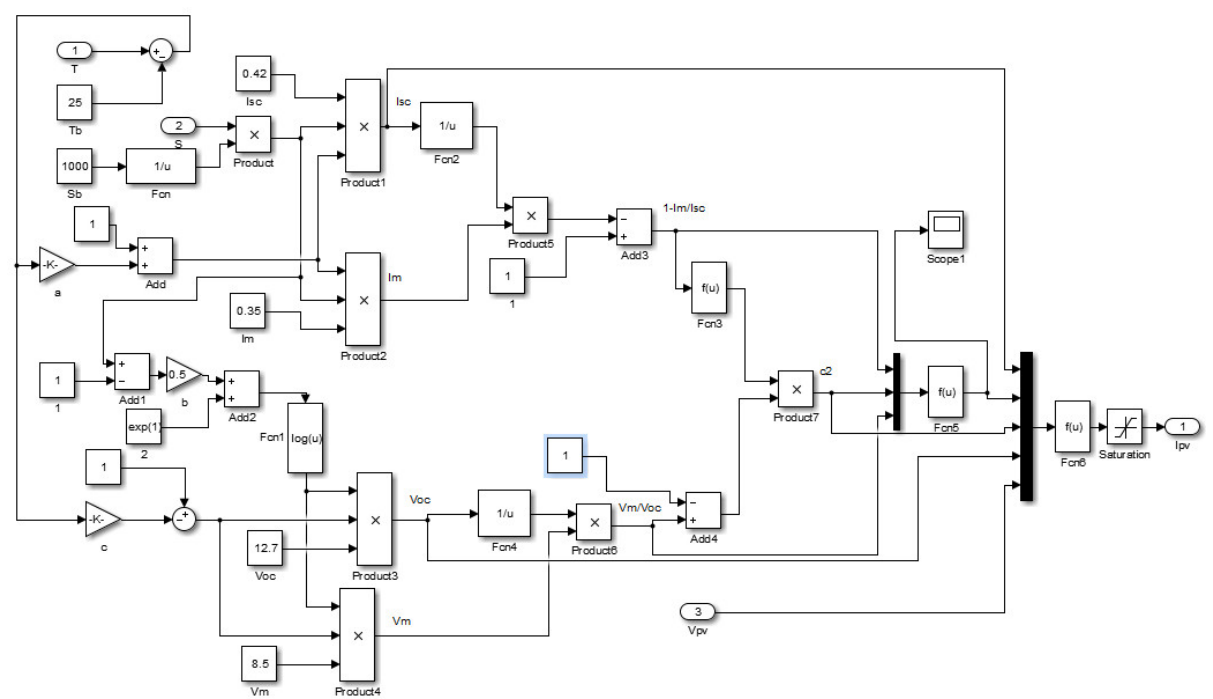

Fig. 2. Photovoltaic cell output characteristics simulation model

\subsection{Analysis of photovoltaic cell output characteristics}

The simulation model of photovoltaic cell is used to simulate the influence of light intensity and temperature on the output characteristic curve of photovoltaic cell, as shown in Fig 3 and Fig4.

The simulated temperature was set at $25^{\circ} \mathrm{C}$ and the light intensity was taken as $200 \mathrm{~W} / \mathrm{m}^{2}, 400 \mathrm{~W} / \mathrm{m}^{2}, 600 \mathrm{~W} / \mathrm{m}^{2}, 800 \mathrm{~W} / \mathrm{m}^{2}, 1000 \mathrm{~W} / \mathrm{m}^{2}$ and $1200 \mathrm{~W} / \mathrm{m}^{2}$, Figure 3 shows the U-P and U-I characteristic curve. Analysis of Figure 3(a), each curve has a highest point, when the light intensity increases in order, the maximum power is also gradually increased, but the fluctuations of maximum power point voltage are not large. In Fig3(b), as the light intensity increases, the shortcircuit current $\mathrm{I}_{\mathrm{SC}}$ increases obviously and the change of open circuit voltage $\mathrm{U}_{\mathrm{OC}}$ is small. 


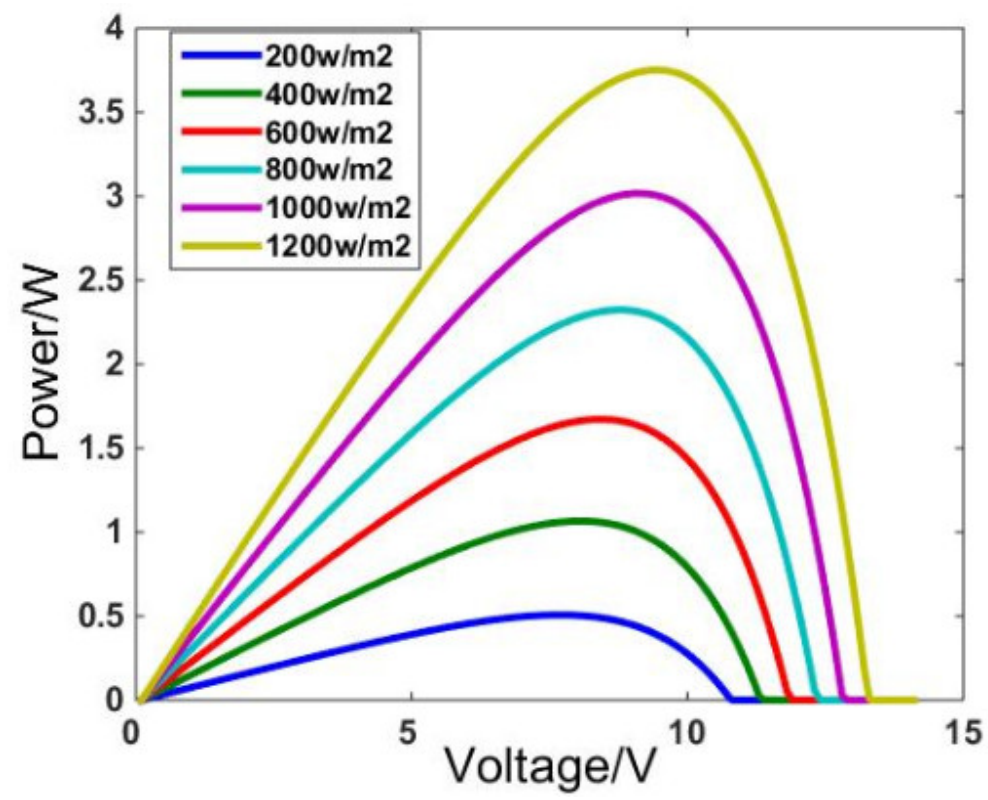

(a) U-P characteristic curve

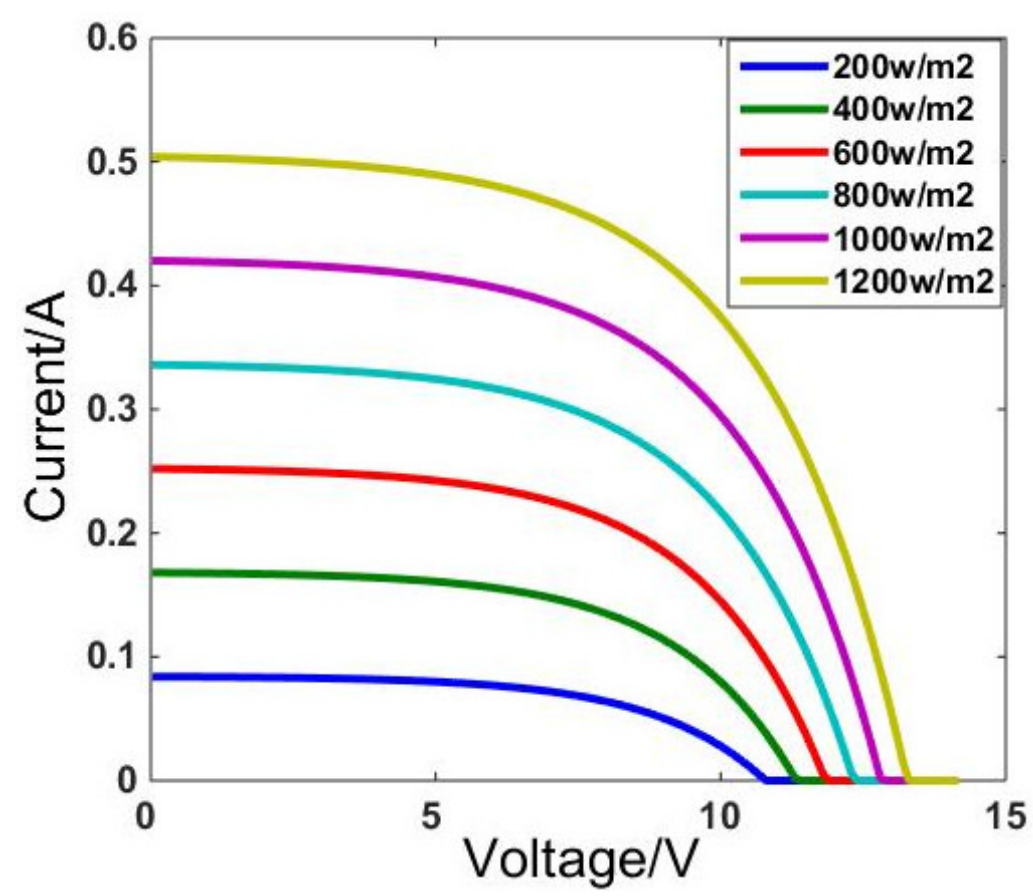

(b) U-I characteristic curve

Fig. 3. Characteristic curve of photovoltaic cells affected by the light intensity 


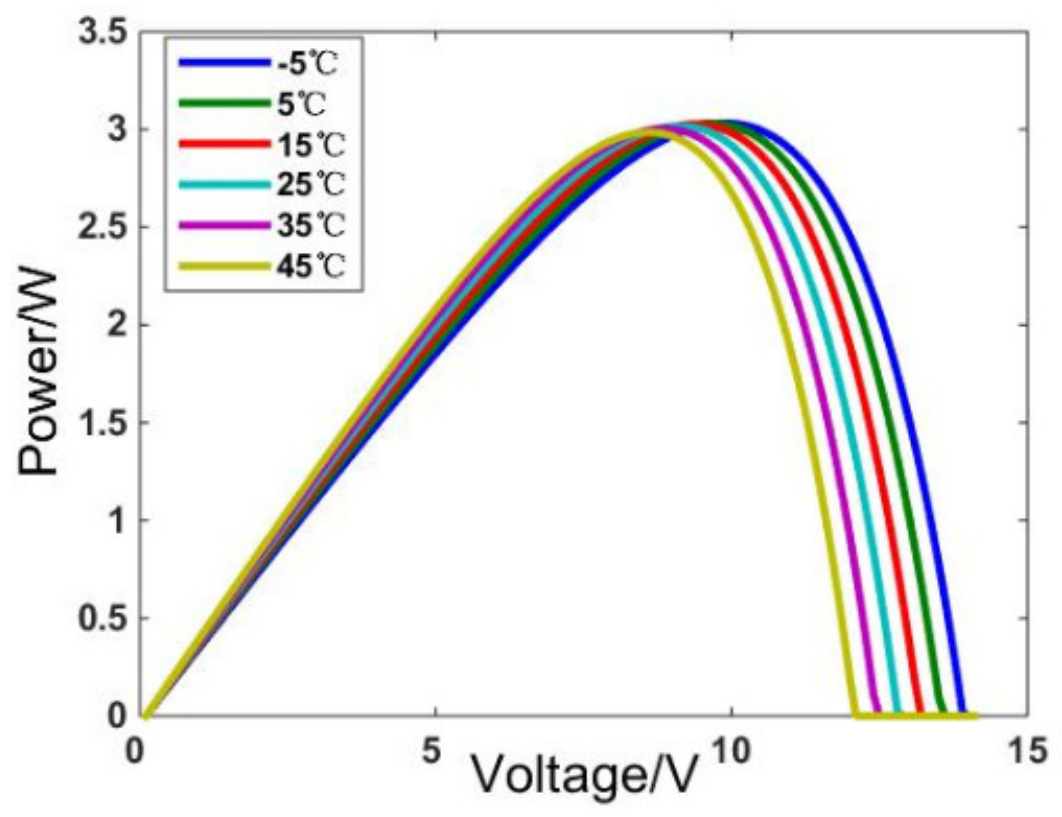

(a) U-P characteristic curve

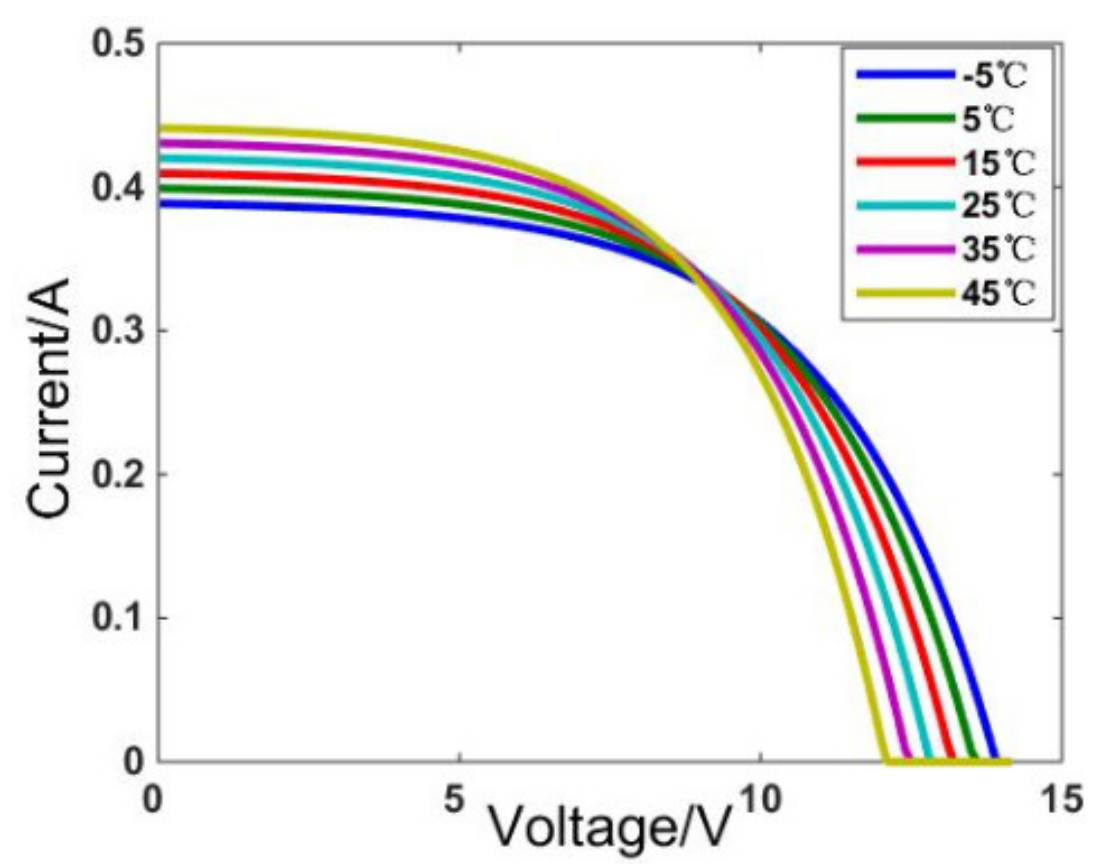

(b) U-I characteristic curve

Fig. 4. The characteristic curve of photovoltaic cells affected by the light intensity 
The simulation light intensity was set to $1000 \mathrm{~W} / \mathrm{m}^{2}$, and the temperature were taken as $-5^{\circ} \mathrm{C}, 5^{\circ} \mathrm{C}, 15^{\circ} \mathrm{C}, 25^{\circ} \mathrm{C}, 35^{\circ} \mathrm{C}$ and $45^{\circ} \mathrm{C}$, Figure 4 shows the U-P and U-I characteristic curve. In Fig 4(a), the power value of the maximum power point increases as the temperature of the photovoltaic panel increases. In the rising stage of the power value, the power does not change substantially when the temperature changes.As shown in Fig 4(b), as the temperature rises, the shortcircuit current increases, while the open circuit voltage decreases with increasing temperature.

Therefore, the change of illumination intensity does not change the maximum power point voltage. Temperature is the main factor that affects the maximum power point voltage, which is caused by the characteristics of the semiconductor material.

\section{Designof MPPT Algorithm}

\subsection{The disturbance observation method}

Thedisturbance observation method is the most commonly used algorithm for MPPT. By applying a small perturbation to voltage or current, the output power before and after perturbation is compared. If the power becomes larger, the perturbation is applied in the direction of the previous disturbance. If the power becomes smaller, the disturbance is applied in the opposite direction of the previous disturbance until the maximum power point is found. The algorithm is easy to implement [18-20]. The algorithm flow chart is shown in Figure 5.

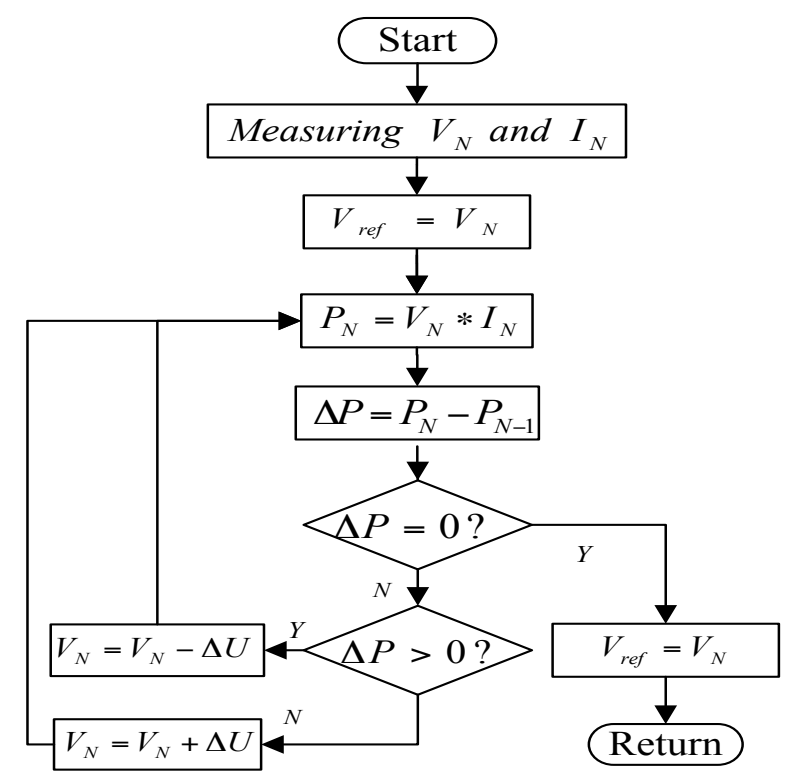

Fig. 5. The disturbance observation method flow chart 
However, because the disturbance observation method needs to collect the voltage and current separately, the power can be calculated and compared to determine the direction of the disturbance, but a large amount of calculation increases the system load. Moreover, the initial value of the voltage or current used in the disturbance observation method and the perturbation step has a great influence on the accuracy and the convergence speed of the algorithm. And oscillation occurs near the maximum power point, resulting in energy loss.

\subsection{The current observation method}

It can be seen from the photovoltaic characteristic curve that the change of light intensity is not significant for the change of the maximum power point voltage. The variation of light intensity is generally regular, so the trend of voltage fluctuation of photovoltaic cells can also be predicted. Before the voltage of photovoltaic cells passes through the voltage stabilizing circuit before entering the load, the voltage change of the load terminals is small. Therefore, voltage unchanged basically when the maximum power point of the photovoltaic cells was tracked. Therefore, the maximum power point of the photovoltaic cell can be analyzed only by monitoring the current at the load end.

The current observation method is as follows: first measure the voltage $V_{N}$ and the current $\mathrm{I}_{\mathrm{N}}$ at the output of the photovoltaic cell, and let the current $\mathrm{I}_{\text {ref }}=\mathrm{I}_{\mathrm{N}}$ at the maximum power point, and apply the disturbance signal through the PWM to change the duty cycle of the FET so that the current changes, resulting in disturbance current. By monitoring the load current and photovoltaic cell input size changes, you can determine the direction of the next disturbance. The current observation method flow chart is shown in Figure 6.

The current observation method can monitor the maximum power point of the photovoltaic cell by simply monitoring the current of the load terminal, which can effectively reduce the calculation amount and reduce the energy loss caused by the extra calculation of the MCU. 


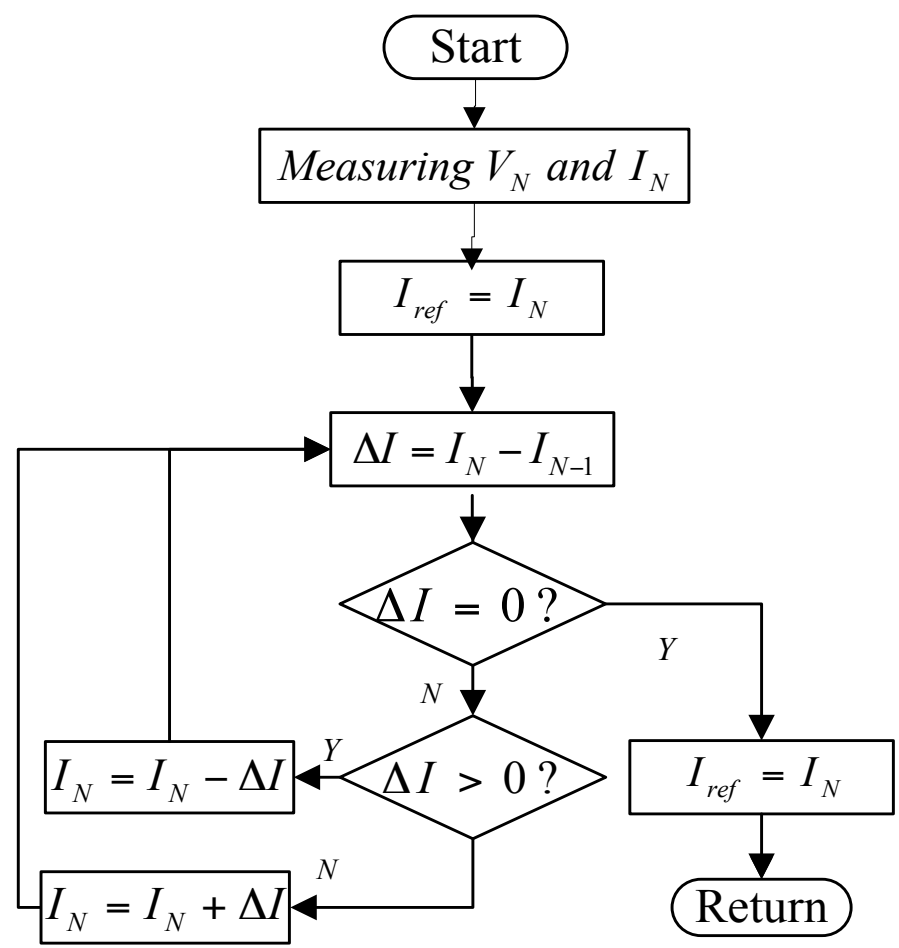

Fig. 6. The current observation method flow chart

\section{ReferencesDesigns of Hardware Circuit and Analysis of Experiment}

\subsection{Designs ofhardware circuit}

The key of the current observation method can be used is that the part of the load voltage is essentially unchanged. Buck circuit is composited by the diode D2, inductor L and capacitor C3. Resistors R2, R3, R4 and R5 all play the role of resistor divider, the capacitor $\mathrm{C} 2$ and $\mathrm{C} 4$ play the role of filter regulator, Buck circuit shown in Figure 7.

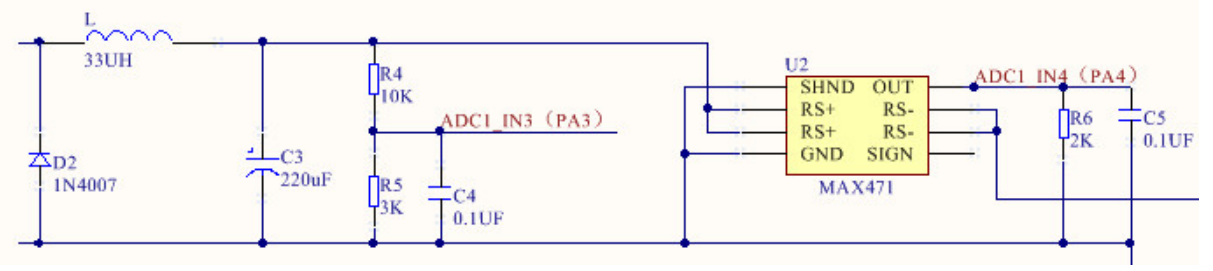

Fig. 7. The Buck circuit 
MPPT circuit is composited by the half bridge driver IC IR2104 and two drive tube SI2302, the circuit is essentially a half bridge drive circuit. By inputting the PWM signal to the IN port of the IR2104 chip, the trend of the current change can be observed by the MAX471 current detection chip. The current trend of U1 and U2 determines the adjustment direction of the next PWM. Taking into account the changes in light intensity is slow generally, in order to reduce the energy loss due to MCU calculations, the maximum power point tracking circuit generally 5 minutes to make a regulation.

The MPPT circuit is shown in Figure 8, in order to prevent the photovoltaic cell voltage drop led to the emergence of lithium batteries or super capacitor voltage back when the light is dim, the photovoltaic cell will first pass through a diode before access the circuit. The current detection chip adjust the current output amplitude through the resistor R1, the capacitor C1 plays a role in stabilizing the filter, the diode D3 and the capacitor $\mathrm{C} 0$ play a self-excitation of the module.

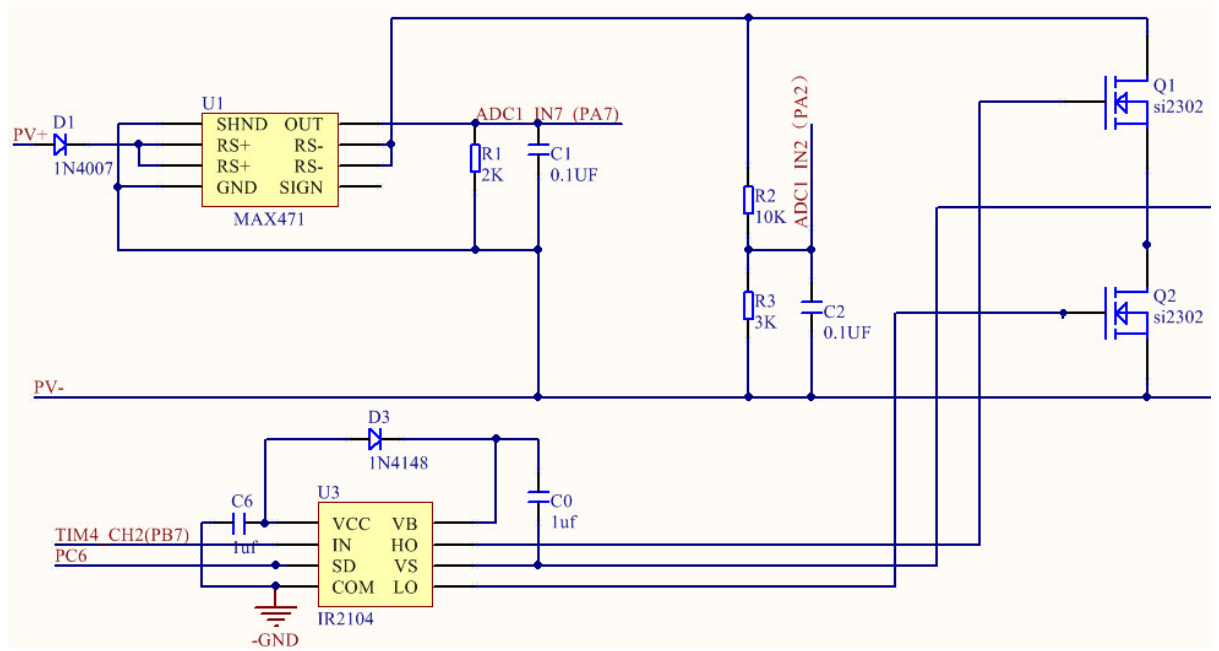

Fig. 8. The MPPT circuit

\subsection{MPPT efficiency experiment and analysis}

Analyzing theMPPT circuit efficiency through the constant voltage source simulation photovoltaic cell voltage, the oscilloscope records the load voltage and current data, and calculated according to these data MPPT circuit efficiency. The experimental setup is shown in Figure 9, and the experimental data is shown in Table 2. 


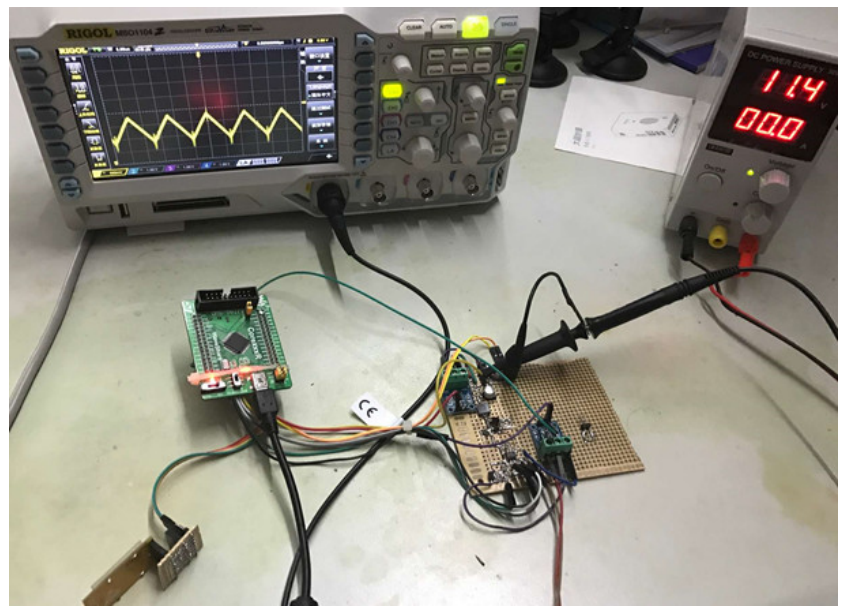

Fig. 9. MPPT efficiency analysis experiment device

As can be seen from the data in Table 2, the efficiency of photovoltaic cells remained stable at above $90 \%$, which is in line with the design requirements of photovoltaic cells tracking. However, the efficiency of photovoltaic cells declined during the decline of photovoltaic cells from $12 \mathrm{~V}$ to $8 \mathrm{~V}$. Because the experiment is in a laboratory, it is a simulation environment.As the input energy increases, the corresponding energy dissipation of the module may also increase correspondingly, resulting in MPPT circuit lower efficiency when the input voltage is larger.

Table 2. MPPT circuit efficiency

\begin{tabular}{|c|c|c|c|c|}
\hline Supply voltage & Input Current & Load voltage & Load current & Efficiency \\
\hline $12.0 \mathrm{~V}$ & $115 \mathrm{~mA}$ & $4.2 \mathrm{~V}$ & $297 \mathrm{~mA}$ & $90.3 \%$ \\
\hline $11.0 \mathrm{~V}$ & $109 \mathrm{~mA}$ & $4.17 \mathrm{~V}$ & $261 \mathrm{~mA}$ & $90.8 \%$ \\
\hline $10.0 \mathrm{~V}$ & $102 \mathrm{~mA}$ & $4.23 \mathrm{~V}$ & $220 \mathrm{~mA}$ & $91.3 \%$ \\
\hline $9.0 \mathrm{~V}$ & $95 \mathrm{~mA}$ & $4.19 \mathrm{~V}$ & $185 \mathrm{~mA}$ & $90.8 \%$ \\
\hline $8.0 \mathrm{~V}$ & $84 \mathrm{~mA}$ & $4.21 \mathrm{~V}$ & $146 \mathrm{~mA}$ & $91.5 \%$ \\
\hline
\end{tabular}

\subsection{Analysis of MPPT circuit experimental}

In the laboratory with adjustable brightness fluorescent lamp experiment, adjust the light intensity, analysis of photovoltaic cell MPPT circuit efficiency. The current detection frequency of output current is once per second, gradually increase the light intensity at $70 \mathrm{~s}$, the data is sent to the host computer through the communication module to record. The communication module's power is $13 \mathrm{~mW}$ as the load. The experimental data is shown in Figure 10. 


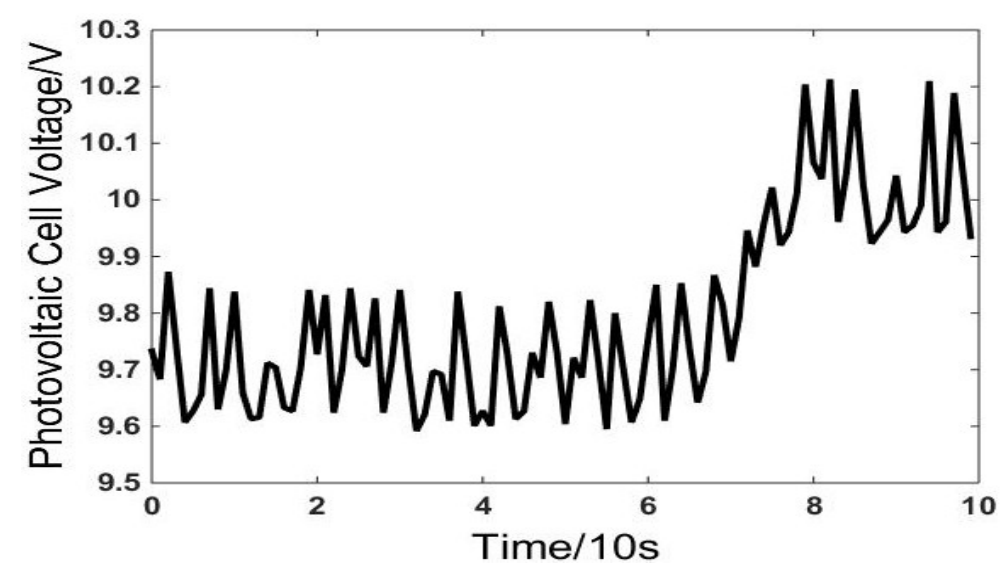

(a) Photovoltaic cell input voltage curve

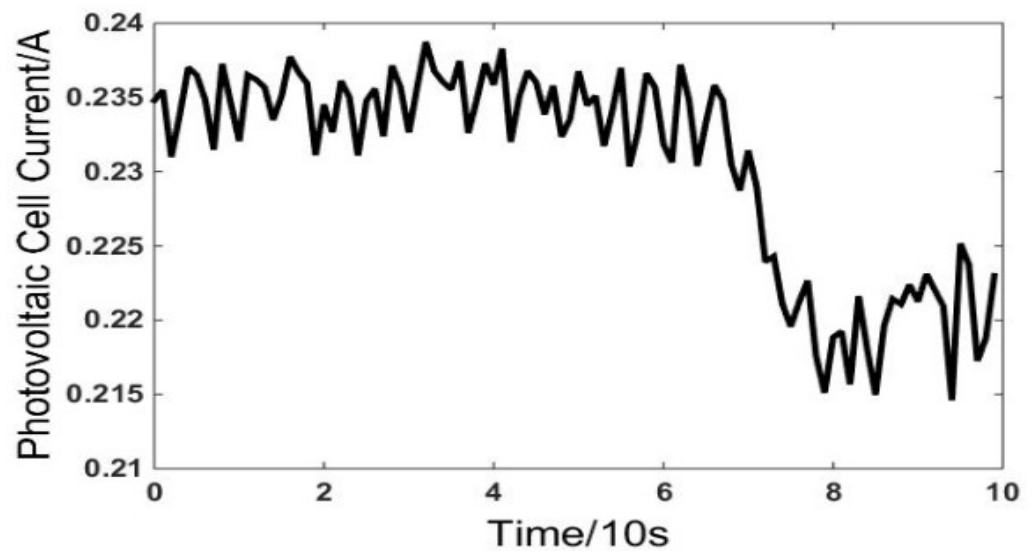

(b) Photovoltaic cell input current curve

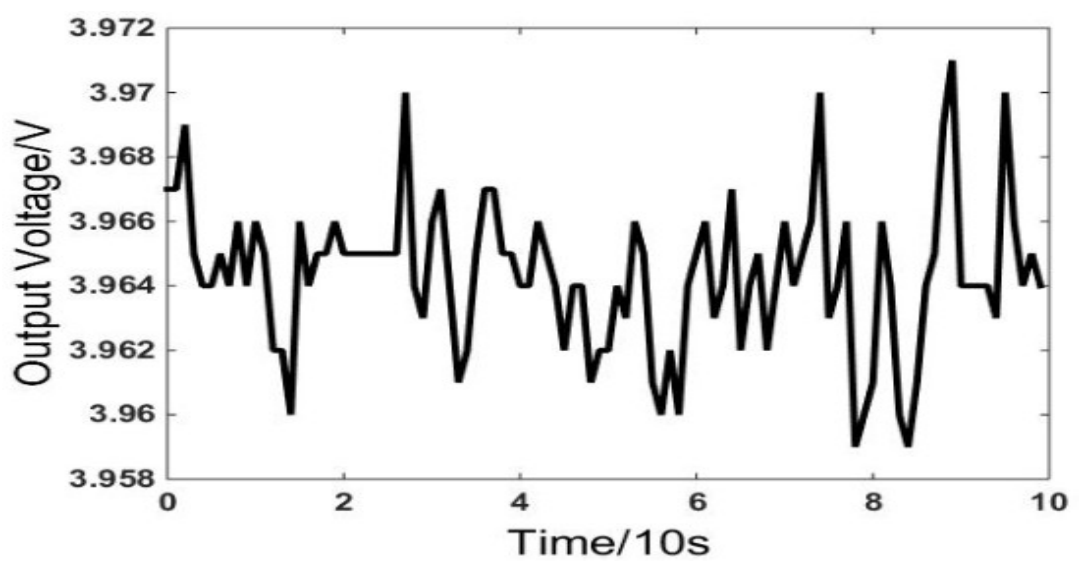

(c) Power supply output voltage curve 


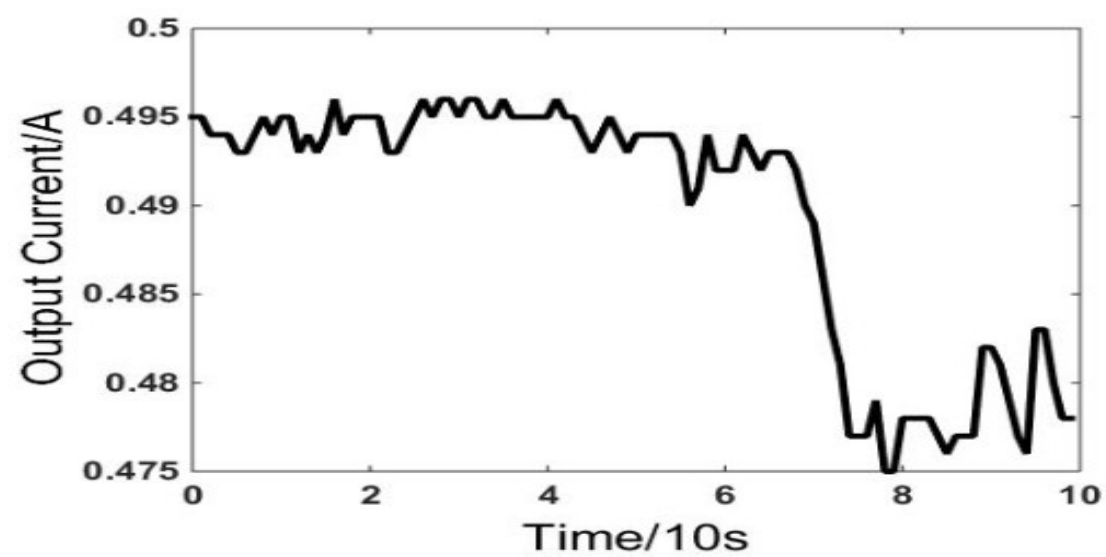

(d) Power supply output current curve

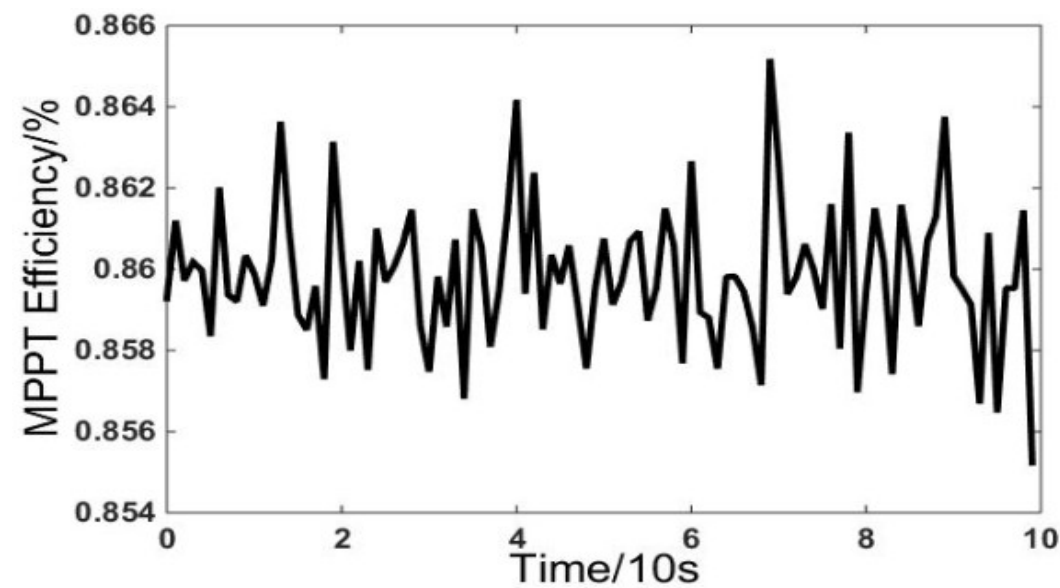

(e) MPPT efficiency curve

Fig. 10. The data of MPPT experiment

In Figure 10, from Figure (a) to Figure (e) are respectively the cell voltage, the five curves are the photovoltaic cell current, the step-down voltage after the MPPT circuit, the step-down voltage after the MPPT circuit, and the overall efficiency of the MPPT circuit. As can be seen from Figure 9, when the fluorescent lamp is kept at low light conditions, the input voltage of the photovoltaic cell is $9.7 \mathrm{~V}$, and the input current of the photovoltaic cell is about $0.234 \mathrm{~A}$. When the fluorescent lamp rises to higher light conditions, the input voltage of the photovoltaic cell is raised to $10.1 \mathrm{~V}$, and the input current is reduced to $0.22 \mathrm{~A}$. This is because as the light intensity increases, the input voltage of the photovoltaic cell increases, and the input current to decrease, which is caused by the change of the external parameters of the photovoltaic cell. For the power output, the output voltage fluctuations is not changewhen the light intensity changes. When the light intensity increases, the output current decreases, butthe MPPT effi- 
ciency fluctuations have not changed and remained fluctuation at about $86 \%$. Therefore, the current observation methodprotects the tracking efficiency of the overall circuit by the optimal adjustment of the input energy.

As the communication module has been in the sending state will result in energy loss, this part can be calculated, the system includes Buck circuit and MPPT circuit, the overall loss of efficiency is about $87 \%$ and the MPPT circuit efficiency is $91 \%$. Therefore, the overall circuit loss of efficiency is low. When the external conditions are changed, the tracking effect of the current observation method does not have any effect, and the energy consumption in the MPPT circuit and the buck circuit is low, which is in line with the design requirements of the overall energy supply circuit.

\section{Conclusions}

The paper establishes the model of photovoltaic cell through the mathematical model, obtains the photovoltaic characteristic curve by simulation, analyzes the photovoltaic characteristic, proposes the current observation MPPT algorithm based on the disturbance observation method, and improves the energy utilization rate. The current observation MPPT circuit is designed, the working efficiency of the current observation method is verified through experiments, and the performance of the energy supply circuit is verified. The experimental results show that the MPPT circuit has good tracking performance and the tracking efficiency is not affected by the change of external conditions. The energy consumption of the overall energy supply circuit is lower, which meets the design requirements of self-powered WSN nodes.

In the experiment, it is found that under different temperature and illumination conditions, the photovoltaic model established according to the mathematical model has some errors with the actual photovoltaic model. Establishing an accurate photovoltaic cell model is helpful to reversely determine the maximum of photovoltaic cells according to different temperature and light conditions Power point. Therefore, the establishment of accurate photovoltaic cell model is the next stage to be solved.

\section{Acknowledgment}

This work was supported by National Natural Science Foundation of China (No. 61741303, No. 61662018), Guangxi Natural Science Foundation(NO. 2017GXNSFAA198161), the key laboratory of spatial information and geomatics (Guilin University of Technology)(No.15-140-07-23, No.16-380-25-23).

\section{$7 \quad$ References}

[1] Wang Chuanchuan, Sun Xia, Qian Hui and Xu Yandong, Study on MPPT of selfseeking optimal perturbation method, Application of Electronic Technique, vol.42, no.7, pp. $142-$ $145,2016$. 
[2] Han Lei, Research on miniature photovoltaic power system for wireless sensor network nodes, Tianjin: Nankai University, 2013, pp.33-42.

[3] Antonio Augusto Frohlich, Eduardo Augusto Bezerra and Lenonardo Kessler Slongo, "Experimental analysis of solar energy harvesting circuits efficiency for low power applications," Computers and Electrical Engineering, vol.45, no.2015, pp.143-154, 2015.

[4] Peng Cao, Research on Energy Management of WSN Node Based on Photovoltaic Energy Supply, Guilin: Guilin University of Technology, 2017, pp.38-47..

[5] W. Xiao,N. Ozog,and W. G. Dunford,Topology study of photovoltaic interface formaximum power point tracking, IEEE Transactions on Industrial Electronics, vol.54, no.3, pp.1696-1704, 2007. https://doi.org/10.1109/TIE.2007.894732

[6] HemalathaRAJENDRAN, Ramaprabha RAMABADRAN, and Radha SANKARARAJAN, Design and Implementation of PV based EnergyHarvester for WSN Node with MAIC algorithm, Advances in Electrical and Computer Engineering, vol.15, no.2, pp.109-116, 2015. https://doi.org/10.4316/AECE.2015.02014

[7] Hu Wentao, Zhang Danhong, Liu Mingjuan and Li Yadi, Research on a MPPT controller suitable for solar UAV, The Technology of Power, vol.40, no.10, pp.1961-1963, 2016.

[8] Han Lei, Zhang Xiaoxing, Dai Yujie and LvYingjie,MPPT algorithm analysis and hardware implementation for micro-photovoltaic system, Journal of Central South University (Science and Technology), vol.44, no.10, pp.4124-4129, 2013.

[9] Hongbin Chen, Xueyan Li and Feng Zhao,A Reinforcement Learning-Based Sleep SchedulingAlgorithm for Desired Area Coverage inSolar-Powered Wireless Sensor Networks, IEEE Sensors Journal, vol.16, no.8, pp.2763-2774, 2016. https://doi.org/10.1109/ JSEN.2016.2517084

[10] AlivaraniMohapatra, ByamakeshNayak and K. B. Mohanty. Performance improvement in MPPT of SPV system using NN controller under fast changing environmental condition, IEEE 6th International Conference on Power Systems, 2016, 1-5.

[11] Liu Pengyu, A hybrid indoor ambient light and vibration energy harvesting micro-power system, Chongqing: Chongqing University, 2013, pp.32-40.

[12] Li Ke, Yang Xue and Shu Shuang, MPPT algorithm for wireless sensor network solar power system, J Tsinghua Univ(Sci\& Tech), vol.51, no.5, pp.597-600, 2011.

[13] Wang Yaoqiang, Zhang Meiling and Qi Ge, Study on improved type perturbation observation for maximum power tracking of PV generation systems, Power Capacitor \& Reactive Power Compensation, vol.37, no.4, pp.111-114, 2016.

[14] C. Bachmann,M. Ashouei,V. Pop, and M. Vidojkovic, Low-power wireless sensor nodes for ubiquitous long-term biomedical signal monitoring. IEEE Communications Magazine, vol.50, no.1, pp.20-27, 2012. https://doi.org/10.1109/MCOM.2012.6122528

[15] Rizvi S, Qureshi HK, Ali Khayam S, Rakocevic V, Rajarajan M. A1,An energy efficient topology control algorithm for connected area coverage in wireless sensor networks. Journal of Network Computer Application, vol.35, no.2, pp.597-605, 2012. https://doi.org/10.1016/j.jnca.2011.11.003

[16] R. Nallusamy, K. Duraiswamy, Solar powered wireless sensor networks for environmental applications with energy efficient routing concepts: A review. Information technology journal, vol.10, no.1, pp.1-10, 2011.

[17] Duy C. Huynh, Matthew W. Dunnigan, Maximum Power Point Tracking Using an Adaptive Perturbation and Observation Algorithm for a Grid-Connected Solar Photovoltaic System.International Journal of Grid Distribution Computing, vol.8, no.3, pp.97-110, 2015. https://doi.org/10.14257/ijgdc.2015.8.3.10 
[18] Ayman Eltaliawy, Hassan Mostafa, Yehea Ismail, Micro-scale variation-tolerant exponential tracking energy harvesting system for wireless sensor networks. Microelectronics Journal, vol.46, no.2015, pp.221-230, 2015.

[19] Yin Li, Ronghua Shi, An intelligent solar energy-harvesting system for wireless sensor networks. Wireless Communications and Networking,vol.17, no.9, pp.1-12, 2015. https://doi.org/10.1186/s13638-015-0414-2

[20] Hoonki Kim, Young-Jae Min, Chan-Hui Jeong, Kyu-Young Kim, Chulwoo Kim, and Chulwoo Kim. A 1-mW Solar-Energy-Harvesting Circuit Using an Adaptive MPPT With a SAR and a Counter. IEEE Transactions on Circuits and System-II: Express Briefs, vol.60, no.6, pp.331-335, 2013. https://doi.org/10.1109/TCSII.2013.2258262

\section{Authors}

Lieping Zhang is currently a professor of college of mechanical and control engineering at Guilin University of Technology, Guilin, China, 541004. His research interests include wireless sensor network, and system optimization. He is also affiliated with the Guangxi Key Laboratory of Spatial Information and Geomatics.(zlp_gx_gl@163.com).

Yanlin $\mathbf{Y u}$ is now pursuing her master degree in college of mechanical and control engineering at Guilin University of Technology, Guilin, China, 541004. Her research interests include wireless sensor network and its application.

HangMa is now pursuing his master degree in college of mechanical and control engineering at Guilin University of Technology, Guilin, China, 541004. His research interests include wireless sensor network and its application.

Yu Zhang is currently an associate professor of college of mechanical and control engineering at Guilin University of Technology, Guilin, China, 541004. Her research interests include wireless sensor network, and photovoltaic power generation system.

PengCao is now pursuing his doctorate in school of automation at Guangdong University of Technology, Guangzhou, China, 510006. His research interests include wireless sensor network and its application.

Article submitted 24 February 2018. Resubmitted 27 April 2018. Final acceptance 17 May 2018. Final version published as submitted by the authors. 